\title{
Mapeamento dos MunicíPios CoM Ensino de Italiano em Escolas Públicas
}

\author{
Fernanda Ortale* \\ Fábio Jorge DE Almeida ZorZAN**
}

RESUMO: O objetivo deste artigo é apresentar um mapeamento dos municípios do Brasil que possuem ensino de italiano em escolas públicas, mas primeiramente tratamos dos documentos oficiais que regulamentam o papel das línguas estrangeiras na Educação Básica. Embora tenhamos realizado um levantamento da situação em cada estado do Brasil, reconhecemos que os dados obtidos podem não cobrir toda dimensão territorial de nosso país. A análise dos dados nos permite afirmar, primeiramente, que há um conhecimento parcial, por parte de órgãos e instituições, acerca da realidade do ensino de italiano em contexto público; em segundo lugar, que, de forma surpreendentemente positiva, o ensino de italiano está presente não apenas nas escolas públicas no sudeste e no sul, mas também em outras regiões do país.

PALAVRAS-CHAVE: mapeamento dos municípios do Brasil; ensino de italiano; escolas públicas.

ABSTRACT: Lo scopo di questo lavoro è presentare un panorama delle città brasiliane che offrono corsi di italiano nelle scuole pubbliche, ma prima discutiamo i documenti ufficiali che regolano l'offerta delle lingue straniere. Malgrado abbiamo

\footnotetext{
* Docente da Área de Língua e Literatura Italiana da Universidade de São Paulo (USP).

**Mestrando USP, bolsista do CNPq.
} 
realizzato un rilevamento delle offerte relative ai corsi di italiano in Brasile, riconosciamo che i nostri dati possono essere incompleti. L'analisi dei dati ci permette di affermare, in primo luogo, che molte istituzioni e associazioni italiane non conoscono la realtà delle offerte dei corsi di italiano; in secondo luogo, possiamo dire che, in modo sorprendente e positivo, l'insegnamento dell'italiano si trova presente non solo nelle scuole pubbliche del sud e sud ovest, ma anche in altri posti del paese.

PAROLE CHIAVE: mappatura dei comuni brasiliani; insegnamento dell'italiano; scuole pubbliche.

ABSTRACT: The aim of this paper is to present a mapping of the cities in Brazil which have Italian language teaching in public schools, but first take care of the official documents governing the role of foreign languages in basic education. Although we conducted a survey of the situation in each state of Brazil, we recognize that the data can not cover the entire territorial dimension of our country. Data analysis allows us to state, first, that institutions have only a partial knowledge of the reality of Italian teaching in public context; secondly, that it is a positive surprise that Italian teaching is present not only in public schools in the Southeast and in the South of Brazil, but also in other regions of the country.

KEYWORDS: mapping of Brazilian municipalities; Italian teaching; public schools. 


\section{Introdução}

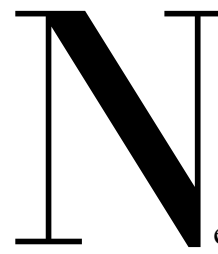

este artigo, apresentaremos um mapeamento dos municípios brasileiros que possuem oferta de italiano em escolas da rede pública. Nosso ponto de partida será uma reflexão sobre as potencialidades de inserção da língua italiana nesse contexto, com base em textos oficiais que regulamentam essa questão.

Atualmente, no Brasil, vigoram dois documentos que estabelecem as diretrizes para a educação e orientam a sua implementação em diversos os níveis: a Lei de Diretrizes e Bases da Educação (LDB) e os Parâmetros Curriculares Nacionais (PCNs).

Conforme assinala Paiva (2003), nos anos anteriores à promulgação da LDB de 1996, o ensino de língua estrangeira (LE doravante) não era obrigatório, pois as LDBs de 1961 e de 1971 não incluíam a disciplina de LE no rol de matérias obrigatórias e deixavam a cargo dos 
conselhos estaduais a introdução ou não do ensino de LE no currículo.

Da mesma forma, a obrigatoriedade do ensino de LE se repete em relação ao Ensino Médio, conforme podemos ver no artigo 36, inciso III:

Será incluída uma língua estrangeira moderna, como disciplina obrigatória, escolhida pela comunidade escolar, e uma segunda, em caráter optativo, dentro das disponibilidades da instituição. (grifo nosso)

Vale ressaltar que a LDB não estabelece a LE a ser ensinada, mas faculta à comunidade escolar a escolha da mesma. Diante disso, o que cada comunidade deveria levar em consideração ao decidir qual LE incluir no currículo escolar? O caput do artigo 26 estabelece que:

Os currículos do ensino fundamental e médio devem ter uma base nacional comum, a ser complementada, em cada sistema de ensino e estabelecimento escolar, por uma parte diversificada, exigida pelas características regionais e locais da sociedade, da cultura, da economia e da clientela. (grifo nosso)

Os PCNs de LE vêm ao encontro do que determina a LDB, na medida em fornecem três fatores que devem ser considerados como critérios para inserir uma LE no currículo: fatores históricos, fatores relativos às comunidades locais e fatores relativos à tradição.

Quando examinamos mais de perto o caput do artigo 26 da LDB onde lemos que as características regionais e locais da sociedade, da cultura, da economia e da clientela devem ser determinantes para a inclusão da LE, nos perguntamos o porquê de a língua italiana (doravante LI) não ocupar um espaço maior no contexto do ensino público brasileiro.

Se as relações culturais, afetivas e de parentesco entre comunidades de imigrantes poderiam se constituir em uma justificativa para a inserção de uma língua estrangeira no currículo, certamente, o ensino de italiano poderia estar presente em quantidade bem maior nas escolas de Educação Básica, já que a imigração italiana foi, de fato, representativa entre o final do século XIX e o início do século XX.

Segundo Trento (1989), no período compreendido entre 1880 e 1924, chegaram ao Brasil mais de 3.600.000 imigrantes, dos quais $38 \%$ eram constituídos por italianos. No entanto, se for considerado somente o período de $1880-1904$, esse percentual sobre para $57,4 \%$, de 
acordo com o estudioso e, segundo dados apontados por Derenzi (1974), nesse último período, desembarcaram no Brasil 984.960 de italianos.

A breve incursão pelos documentos oficiais teve como objetivo demonstrar a existência de um espaço, oficialmente aberto, para o ensino de línguas estrangeiras não hegemônicas nas escolas públicas. Apresentaremos, então, a descrição da situação do ensino de italiano em contexto público nos estados do Brasil ${ }^{1}$.

\section{O Ensino da Língua Italiana nos Municípios do Brasil}

A coleta de dados relativos às escolas públicas onde se ensina a língua italiana foi segmentada por estado da federação. Além da consulta ao Consulado Italiano de São Paulo, procuramos contatar, em cada um dos estados: as universidades brasileiras que oferecem cursos de Graduação em língua italiana (LI doravante), o representante consular da região e as associações ítalobrasileiras.

Procuramos pesquisar ainda, dados na internet ou contatar as secretarias municipais de educação, bem como profissionais indicados pelas universidades, pelas associações ítalobrasileiras ou pelos consulados que poderiam fornecer dados mais precisos.

Elencamos a seguir, os municípios, agrupados por estados ou regiões do Brasil, nos quais verificamos a presença do ensino público de italiano em escolas brasileiras.

\section{Rio Grande do Sul}

Segundo Trento (1989), a verdadeira colonização italiana no sul do Brasil começou em 1875 com números mais expressivos no estado do Rio Grande do Sul quando as primeiras famílias italianas fundaram o núcleo de Nova Milano, hoje um distrito do município de Farroupilha. A partir daquele ano vários outros italianos provenientes das regiões do Vêneto, da Lombardia e de Trento se estabeleceram em diferentes áreas do estado destinadas à imigração italiana, onde hoje se encontram as cidades de Bento Gonçalves, Caxias do Sul, Garibaldi e Nova Trento. Segundo o autor, de 1882 a 1914, entraram no estado gaúcho 66.901 italianos e, embora não haja dados oficiais que comprovem o número de italianos chegados entre 1875 e 1882, estima-se que por ano chegassem cerca de 3.000 italianos.

No estado do Rio Grande do Sul, há um convênio entre uma associação italiana e as prefeituras de diversas cidades do estado para que a LI seja ensinada, na maioria dos casos, nas séries iniciais do ensino fundamental, ou seja, do $1^{\circ}$ ao $5^{\circ}$ ano. Nesse convênio, a Associação

1 Tal descrição encontra-se na “Tabela de municípios com ensino de italiano nas escolas públicas” (vide Apêndice). 
Cultural Italiana do Rio Grande do Sul (ACIRS) oferece suporte didático, cursos de preparação e formação da LI aos professores dos municípios envolvidos que, na maior parte, não possuem Graduação em língua italiana e os salários dos professores são pagos pelas próprias prefeituras.

Os municípios que firmaram o convênio com a ACIRS e que inseriram a LI no horário escolar são os seguintes: Antonio Prado, Aratiba, Caxias do Sul, Coqueiro Baixo, Doutor Ricardo, Farroupilha, Imigrante, Nova Brescia, Porto Alegre, São Marcos e Serafina Correa. Já aqueles que inseriram a LI no contraturno são estes: Bento Gonçalves, Faxinal do Soturno, Nova Prata, Nova Roma do Sul, São João do Polesine, Veranópolis e Vista Alegre do Prata.

No que diz respeito à capital do estado, Porto Alegre, o ensino da LI foi implantado na rede municipal de educação há cerca de seis anos por intermédio do convênio firmado com a ACIRS que formou professores através de cursos de língua e cultura italiana. Esses professores já atuavam na rede pública municipal, mas ensinavam outras disciplinas, e após esse curso passaram a ensinar também a LI. Posteriormente, com a oferta da LI na rede, foi viabilizada a realização de um concurso público para professor especificamente para esse idioma, mas embora muitos tenham sido aprovados, apenas uma professora foi nomeada até o momento. Nas escolas da capital gaúcha, a LI é oferecida em horário escolar e a partir do primeiro ano do segundo ciclo de formação. Os alunos têm contato com a LI por aproximadamente dois anos, dependendo da direção da escola, que determina a oferta da LI aos alunos.

\section{Santa Catarina}

De acordo com Trento (1989), a colonização italiana no estado de Santa Catarina foi menos expressiva em relação ao vizinho estado gaúcho. Entre os anos de 1885 e 1894, entraram no estado catarinense 8941 italianos provenientes, sobretudo, das regiões lombarda, vêneta e trentina. Os trentinos se dirigiram para a região norte do estado, fundando a cidade de Nova Trento e "se espalhando pelas colônias da área conhecida como Pomeranos" (TRENTO, 1989, p.86). Já os lombardos e vênetos rumaram para o sul do estado povoando as colônias de Azambuja, Urussanga e Tubarão. Segundo o autor, duas colônias se destacam na história da imigração italiana no estado de Santa Catarina por se tornarem as únicas com predomínio da população italiana: Urussanga, que em 1878, contava com 7000 italianos e Nova Venezia, que em 1884, tinha uma população de 2885 italianos.

Apesar de ser um estado com predomínio da colonização alemã, o ensino da LI encontra espaço no contexto público escolar catarinense. 
O Centro di Cultura Italiana (CCI), por meio de acordos assinados com as prefeituras de vários municípios, levou o ensino gratuito do italiano a milhares de crianças do ensino fundamental do estado catarinense. Nessa parceria, o CCI fornece a formação aos professores, o apoio pedagógico e o material didático. Segundo a coordenadora do CCI, esses professores não possuem formação universitária em língua italiana e todos pertencem ao quadro de funcionários do município, recebendo, portanto, seus salários das próprias prefeituras. Assim, os municípios catarinenses que têm a LI inserida no horário escolar graças a esse acordo são os seguintes: Arroio Trinta, Laurentino, Morro Grande, Nova Veneza, Salto Veloso e Siderópolis . Já os que colocaram a LI no contraturno são: Balneário Camboriú, Concórdia, Jaborá, Jaraguá do Sul, Joinville, Mafra e Massaranduba.

De acordo com Balthazar (2009), além desse convênio entre o CCI e as prefeituras do estado de Santa Catarina que permite o ensino de LI na educação básica, a rede estadual de ensino conta com a LI inserida no currículo escolar e com dez professores efetivos com formação em LI distribuídos em seis escolas dos seguintes municípios: Arroio Trinta, Ascurra, Iomere, Lindóia do Sul, Nova Trento e Rodeio.

\section{Paraná}

De acordo com Caira (2009), os primeiros italianos chegaram ao Paraná em fevereiro do ano de 1975 e um outro grupo em setembro de 1976. Segundo Trento (1989), o primeiro grupo era composto de 50-60 famílias e o segundo era formado por 20 famílias da cidade de Mântova e por mais algumas outras da cidade de Teramo que se instalaram próximo a cidade de Paranaguá, fundando a colônia de Alexandra. Entretanto, pouco tempo depois, a colônia foi abandonada devido a diversos fatores, entre os quais, a insalubridade do terreno, fazendo com que os italianos que ali moravam fossem transferidos para uma nova colônia, Nova Itália, localizada na cidade de Morretes. Em 1880, conforme assinala Trento (1989, p. 88), "um numeroso contingente dirigiu-se para a periferia da capital da província, Curitiba, onde surgiram os principais núcleos habitados por italianos; em 1889 existiam dezesseis núcleos em que viviam cerca de 10.000 italianos". Nos anos seguintes, mais italianos chegaram ao Paraná apesar de em número cada vez menor e quase todos provenientes da região norte da Península.

Em Curitiba o CCI (Centro di Cultura Italiana) firmou parcerias com as prefeituras de algumas cidades paranaenses para a inserção de LI nas escolas públicas. Assim como ocorre em Santa Catarina, a LI é inserida em algumas séries do ensino fundamental, sobretudo nas iniciais, 
e as aulas são ministradas por professores das próprias prefeituras e que não têm formação específica em LI. Cabe ao CCI fornecer todo o suporte para a formação e treinamento desses professores.

Os municípios que inseriram a LI no horário escolar são os seguintes: Curitiba e Mandirituba. Aqueles que introduziram a LI nas escolas no contraturno são: Coronel Vivida, Curitiba (algumas escolas), Palmas, Rio Negro, São João e São José dos Pinhais.

A Secretaria de Educação do Estado também promove o ensino de LI em escolas estaduais como disciplina extracurricular e gratuita a alunos, professores, funcionários e pessoas da comunidade por meio do Centro de Línguas Estrangeiras Modernas (CELEM). Os CELEMs que oferecem a LI se encontram nas seguintes cidades: Cascavel, Céu Azul, Corbélia, Curitiba, Francisco Beltrão, Ibaiti, Maringá, Santa Tereza D’Oeste, São Jerônimo da Serra, Siqueira Campos, Toledo, Vera Cruz do Oeste.

\section{Espírito Santo}

Conforme destaca Derenzi (1974), os primeiros italianos desembarcam no Espírito Santo em 1874, trazidos por Pietro Tabacchi que, em 1832, fundou a fazenda Nova Trento, em homenagem à sua terra natal. Era um grupo de 386 famílias, compostas de adultos e crianças, que se dirigiram para a localidade de Santa Cruz, hoje município de Aracruz e depois para as terras de Nova Trento. Trento (1989) ressalta que o Espírito Santo estava entre as primeiras metas da imigração italiana no Brasil. Nos anos seguintes à chegada da primeira leva de italianos, vários desembarques são realizados nas cidades de Vitória, Anchieta, Barra de Itapemirim e São Mateus. A partir desses locais, os italianos se dispersaram e fundaram colônias em diversas cidades como, por exemplo, Ibiraçu, Santa Teresa, Rio Novo, Alfredo Chaves, Santa Leocádia, Boa Família, Colatina, Nova Venécia, Venda Nova do Imigrante, e Castelo. (DERENZI, 1974) Embora não haja dados precisos sobre o número de imigrantes italianos que entraram no Espírito Santo, pode-se concluir que foi um número considerável porque se estima em cerca de $70 \%$ os descendentes de italianos no estado atualmente.

No estado do Espírito Santo, o ensino da língua italiana nas escolas públicas reduziu-se significativamente em 2013. Até o ano de 2009, as cidades de Vargem Alta e Nova Venécia contavam com o ensino de italiano no contraturno graças a um convênio entre as prefeituras e a Associação de Língua e Cultura Italiana do Espírito Santo (ALCIES), nos mesmos moldes dos convênios realizados pelas associações italianas dos estados do sul do Brasil. Em 2011, Venda 
Nova do Imigrante também firmou convênio com a ALCIES para a inserção do italiano em três escolas do ensino fundamental e, como consequência, outras cidades também se beneficiaram desse acordo: Vitória, Vila Velha, Castelo, Alfredo Chaves, Cachoeiro de Itapemirim.

Entretanto, constatou-se que a situação do ensino de LI no estado capixaba mudou em 2013, devido à crise pela qual passa a Itália. Houve grandes cortes orçamentários, o ensino de LI nas escolas públicas perdeu espaço e hoje está presente apenas em duas cidades do estado: Domingos Martins e Santa Teresa. Na primeira, a LI é inserida do $2^{\circ}$ ao $5^{\circ}$ ano e na segunda, de $2^{\circ}$ até o $8^{\circ}$ ano. Em ambas as cidades, a LI é oferecida no horário escolar e os professores pertencem aos quadros de funcionários das prefeituras, mas cabe à ALCIES fornecer a formação em língua italiana e o material didático.

\section{Minas Gerais}

Segundo TRENTO (1989), embora a imigração italiana em Minas Gerais tenha iniciado em 1850, ela não foi frutífera. No entanto, a partir de 1887 o governo mineiro começou a estimular a imigração, já que os fazendeiros precisavam de mão-de-obra para trabalhar nas lavouras, sobretudo as de café.

Desse modo, não é de admirar que os italianos fossem a nacionalidade predominante entre os imigrantes entrados em Minas Gerais. Greco (2009) mostra que, somente entre 1894 e 1898 , 46.428 italianos entraram no estado para trabalharem nas fazendas. Milhares de outros chegaram nos anos seguintes, conforme Trento (1989).

Em Belo Horizonte há Fundação Torino e a Associação de Cultura Ítalo-Brasileira do Estado de Minas Gerais (ACIBRAMG). A Fundação Torino possui um Centro de Língua e Cultura Italiana que oferece aulas de LI ao público em geral. Parece haver apenas uma escola pública ${ }^{2}$ em Minas Gerais, na cidade de Belo Horizonte, que conta com o ensino de LI patrocinado pela Fundação Torino. Segundo dados obtidos, nessa escola, a LI é ensinada no contraturno por professores da própria Fundação a alunos do $4^{\circ}$ ano e do $9^{\circ}$ ano do ensino fundamental.

2 A Escola Municipal Marconi tem um papel importante na história da imigração italiana em Minas Gerais, pois foi fundada em 1937 por imigrantes italianos ligados ao movimento integralista. 


\section{O Estado de São Paulo}

De acordo com Trento (1989), do final do século XIX até o ano de 1920 chegaram ao estado paulista 1.078.437 italianos. Sendo assim, não é de se admirar que esse contingente tão expressivo tenha contribuído fortemente para o crescimento demográfico da população paulista. Segundo dados do próprio autor em 1934, "imigrantes e filhos nascidos no Brasil representavam 50\% da população paulista". (TRENTO 1989, p.107) Ainda segundo o autor, os municípios onde a imigração italiana foi mais forte foram os situados ao longo das ferrovias Mogiana e Paulista cujos trens facilitavam o escoamento da produção de café. Com o tempo, graças à abertura de novas plantações de café e ao aumento tanto da população quanto da rede ferroviária os italianos se dirigiram para diversas regiões no interior do Estado de São Paulo, de modo que hoje encontramos diversas cidades com forte influência italiana e com um grande número de descendentes.

O ensino de italiano está presente em escolas públicas de São Paulo, graças a um acordo entre a Secretaria Municipal de Educação e a FECIBESP, responsável pela formação linguística e pedagógica de professores da Rede Municipal de Ensino da cidade de São Paulo, por meio de cursos de curta duração. Após a conclusão do curso oferecido pela FECIBESP, parte dos professores, por iniciativa própria, propõe projetos para ensino de italiano no contraturno das escolas onde atuam em salas de Ensino Fundamental.

Além desse contexto, a língua italiana está presente nas escolas estaduais do estado de São Paulo nos Centros de Estudos de Línguas (CEL), espalhados por todo o estado paulista. O objetivo desses centros é oferecer aos alunos da rede estadual a oportunidade de aprender um novo idioma. A língua italiana é oferecida aos estudantes a partir do $7^{\circ}$ ano do Ensino Fundamental, do ensino regular ou Educação de Jovens e Adultos (EJA). O curso tem duração de três anos, divididos em seis módulos semestrais e as aulas, que são no contraturno. Segundo dados obtidos por Rocha ${ }^{3}$ (2013), em todo o estado há 173 CELs em funcionamento, e apenas 31 unidades oferecem cursos de italiano, contando com 1.350 alunos.

Segundo dados oferecidos em 2013 pelo Consulado Italiano, os municípios que oferecem cursos de italiano nos Centros de Línguas são os seguintes: Araçatuba, Araraquara, Assis, Avaré, Carapicuíba, Fernandópolis, Guarulhos, Jales, Santa Fé, José Bonifácio, Mirassol, Nova Granada, Jundiaí, Marília, Osasco, São José do Rio Preto, São José dos Campos, São Paulo, São Vicente, Suzano, Taquaritinga, Taubaté e Tupã.

3 ROCHA, V.G. (2013, p. 28) O ensino da língua italiana nas salas multisseriadas nos Centros de Estudos de Línguas da capital e da Grande São Paulo, Exame de Qualificação de Doutorado, Universidade de São Paulo. 
Além das cidades acima citadas, os municípios de Amparo e Campos de Jordão tomaram a iniciativa de oferecer a LI nas escolas da rede.

No município de Amparo, o ensino de LI foi implantado em 2006, graças a um convênio entre a prefeitura e a Federação das Entidades Culturais Ítalo Brasileiras do Estado de São Paulo (FECIBESP). Segundo a responsável pelo Centro de Formação dos Profissionais de Educação, órgão ligado à Secretaria Municipal de Educação, as aulas de LI, de uma hora e meia de duração, são realizadas duas vezes na semana no contraturno para alunos do $2^{\circ}$ ao $5^{\circ}$ ano do ensino fundamental de três escolas da rede. Os professores pertencem ao quadro de funcionários do município e para dar aulas de LI precisaram fazer um curso de italiano por dois anos e ingressar no processo de formação continuada que prevê a frequência semanal a cursos de LI.

Na cidade de Campos do Jordão, o ensino de LI foi implantado no ano de 2014, fruto de um convênio entre a prefeitura e a FECIBESP. Segundo a Secretaria de Educação do Município, a LI será inserida no contraturno, como oficina, em cinco escolas integrais da rede municipal. Em quatro escolas os alunos do $4^{\circ}$ e $5^{\circ}$ ano serão contemplados com o ensino de LI e em uma escola serão os alunos do $6^{\circ}$ e do $7^{\circ}$ ano que terão esta oportunidade.

Em Jarinu, de acordo com informações da Secretaria Municipal de Educação, o ensino de LI foi implantado na grade curricular escolas da rede no ano de 2004 graças a um convênio entre a prefeitura e FECIBESP. Atualmente as aulas de LI, com duração de 50 minutos, são realizadas apenas uma vez por semana em 11 unidades escolares do município para alunos do $2^{\circ}$ ao $5^{\circ}$ ano do ensino fundamental. Os professores pertencem ao quadro de funcionários do município e para ministrar as aulas precisam realizar cursos de formação em LI.

Em Jundiaí, apesar de não haver o ensino de LI nas escolas da rede, há um Centro de Línguas mantido pela prefeitura que oferece cursos de várias línguas, inclusive de LI, aos moradores da cidade, e as aulas são ministradas por duas professoras concursadas que nos três períodos do dia. O curso tem duração de dois anos e os alunos pagam apenas o material didático.

Em São Caetano do Sul, o ensino de LI foi inserido na grade curricular em 2007. Naquele ano, a LI era ensinada nos primeiros cinco anos do ensino fundamental com duas aulas semanais chamadas de oficinas. Com o passar do tempo, a situação mudou. No ano seguinte à introdução da LI nas escolas públicas de São Caetano, as aulas foram diminuídas de duas para apenas uma aula semanal; depois o ensino de LI foi retirado dos primeiros dois anos do ensino fundamental. Em 2013, a LI só era ensinada uma vez por semana nos $3^{\circ}, 4^{\circ}$ e $5^{\circ}$ anos, sempre no contraturno, em seis escolas integrais do município. A perspectiva para o ano de 2014 era que a LI fosse 
ensinada apenas nos $4^{\circ}$ e $5^{\circ}$ anos. Segundo a informante, a decisão pela retirada da LI ou pela diminuição de sua carga horária no currículo foram tomadas sempre pelas diretorias das escolas devido à falta de professores habilitados para o ensino de língua estrangeira para crianças. Há ainda na cidade a "Escola Municipal de Idiomas Paulo Sérgio Fiorotti", que, segundo o site do próprio município, oferece ensino gratuito de várias línguas, entre as quais a LI, aos moradores da cidade tanto jovens quanto adultos.

Em Pedrinhas Paulista, a LI é inserida na grade curricular da única escola municipal da rede. As aulas são realizadas apenas uma vez na semana com duração de 50 minutos para alunos do $2^{\circ}$ ao $5^{\circ}$ ano do ensino fundamental, e são ministradas por uma professora formada em língua italiana e concursada.

\section{O Estado do Rio de Janeiro}

$\mathrm{Na}$ época da imigração italiana para o Brasil, o Rio de Janeiro era a capital federal e, como os outros estados do país, também recebeu milhares de imigrantes italianos, embora em número menor. Trento (1989) chama a atenção para algumas particularidades da imigração italiana no estado fluminense: a proveniência e a trabalho exercido pelos imigrantes. Conforme o autor, diferentemente dos estados do sul que atraíram, em sua maioria, os italianos setentrionais, no Rio de Janeiro, o contingente maior foi de italianos provenientes das regiões do sul da Itália, principalmente das províncias de Cosenza, Potenza e Salerno e, em número menor, das províncias de Reggio Calabria, Nápoles e Caserta. O ambiente urbano do Rio de Janeiro contribuiu também para que os italianos que aqui chegaram exercessem profissões ligadas ao comércio ambulante bem diferente das exercidas pelos seus patrícios que estavam no sul do Brasil. Do final do século XIX ao início do século XX a população italiana residente no Rio de Janeiro aumentava lenta, mas constantemente, atingindo seu ápice na primeira década do século XX com cerca de 30.000 habitantes, perdendo apenas para os imigrantes de nacionalidade portuguesa. Da capital os italianos se dirigiram para outras cidades do estado e estabeleceram colônias nas cidades de Niterói, Petrópolis, Teresópolis, Nova Friburgo, Varre-Sai, Porto Real e outras.

Durante o levantamento dos dados referentes à situação do ensino de LI no estado do Rio de Janeiro, descobrimos a ocorrência de um concurso público realizado em 2007 pelo governo do estado para o cargo de professor de italiano para escolas de ensino médio. Conforme o

edital do concurso, eram previstas três vagas para docentes de italiano que atuariam cada um 
em três áreas distintas: um na cidade do Rio de Janeiro, um na cidade de Niterói e um na região noroeste do estado. Não se pode afirmar se os candidatos aprovados tomaram posse dos cargos e se ainda atuam no ensino de LI nas escolas estaduais de suas regiões, pois o órgão responsável não soube informar.

Na cidade do Rio de Janeiro, o ensino de LI não consta no currículo escolar. No entanto, por cerca de vinte anos algumas escolas municipais tiveram o ensino de LI inserido no horário escolar graças a um acordo entre a Associação Cultural Ítalo-Brasileira do Rio de Janeiro (ACIBRJ) e a prefeitura da cidade. A escola "Itália" - localizada em Rocha Miranda, e as escolas "Pio X" e "25 de abril" - localizadas no município de Jacarepaguá, ofereciam aulas de italiano na grade curricular, graças a um acordo entre a Prefeitura e ACIB-RJ, esta última responsável pelo envio de professores às escolas. As duas primeiras escolas já haviam deixado de oferecer aulas de italiano desde 2008, mas a Escola Itália foi a última a cancelar suas turmas em 2012, ano em que a ACIB-RJ fechou suas portas por questões orçamentárias.

Atualmente, sabe-se da existência do ensino de LI em uma escola da rede municipal do Rio de Janeiro que funciona no regime chamado de "Ginásio Experimental Carioca". De acordo com o site da secretaria municipal de educação, nessa modalidade de ensino os alunos estudam em horário integral e têm uma carga horária maior de disciplinas como português, matemática, ciências, educação física e inglês. Assim, graças a esse projeto, uma professora da rede, que também é formada em LI, implantou na escola em que trabalha o ensino de LI para alunos do $7^{\circ}$ e do $8^{\circ}$ ano. As aulas ocorrem no contraturno apenas uma vez por semana e duram duas horas. A cada semestre se forma um novo grupo, já que o objetivo do trabalho não é tornar os alunos fluentes de uma LE, mas oferecer a oportunidade para que um maior número possível de estudantes possa conhecer um pouco mais a LI além de aspectos históricos e culturais da Itália.

\section{Os estados do Nordeste}

Pouco se fala da imigração italiana nos estados do Nordeste do Brasil. Isto ocorre porque o número de italianos ali chegados foi bem menor em comparação ao contingente que rumou para os estados do Sul e do Sudeste. Cenni (2002) aponta algumas razões que explicam a falta de interesse dos italianos por essa região do Brasil, entre as quais, o clima não favorável e as culturas do algodão e da cana de açúcar que só podiam ser exploradas em grandes latifúndios dos quais os italianos praticamente não poderiam ser proprietários. Assim, a imigração italiana nessa região foi caracterizada principalmente por indivíduos que se dedicavam a atividades 
essencialmente urbanas.

Entretanto, embora o número de italianos não tenha sido tão expressivo como nos estados do sudeste e sul, desde o período colonial houve uma forte presença italiana na região nordeste, quando vieram, segundo Andrade ${ }^{4}$ (2002, p.39) "como navegadores e exploradores da costa (século XVI) como missionários jesuítas e capuchinhos (séculos XVI, XVII e XVIII), ou como soldados durante o período de domínio espanhol para lutar contra os holandeses”. Mas será a partir da segunda metade do século XIX que os italianos chegarão em maior número, contribuindo expressivamente para o desenvolvimento econômico e cultural da região. (ANDRADE, 2002)

De todos os estados do Nordeste, a Bahia recebeu o maior número de italianos, que vinham sozinhos ou acompanhados por familiares, muitas vezes incentivados por parentes e amigos que aqui já se haviam instalado. Depois de algumas experiências não muito bem-sucedidas em atrair italianos para trabalhar na agricultura em 1936 e na construção da estrada de ferro ligando Salvador a Juazeiro em 1956, os imigrantes que escolheram ficar na Bahia se tornaram ambulantes ou operários especializados em atividades que já exerciam na Itália, como mecânicos, condutores de veículos, marceneiros e alfaiates. Outra leva de imigrantes que a Bahia recebeu no final do século XIX era composta de músicos, professores de música e de desenho, artistas teatrais, cantores e mágicos, todos para agradar e entreter a burguesia da época. Esses italianos, a maioria originários do sul, estabeleceram-se em Salvador, Nazaré das Farinhas, Ilhéus, Itabuna, Feira de Santana, Alagoinhas, Jequié, etc. De acordo com Andrade (2002), atualmente Salvador e Jequié concentram o maior número de italianos e de seus descendentes onde ocupam posições de destaque tanto do ponto de vista econômico e social.

Em nossos levantamos não encontramos a presença do ensino público de italiano na nas escolas públicas do estado da Bahia. Em Salvador há o curso de Letras na Universidade Federal da Bahia, com habilitação em Língua Italiana, além da Associação Itália Amica - Accademia di Cultura Italiana, mas não identificamos nenhuma escola pública onde se ministrassem aulas de italiano, apenas em cursos livres por parte de iniciativas privadas.

Segundo Andrade (2002), o estado de Pernambuco, representado pela sua capital Recife, no início do século XX já abrigava o Consulado Geral da Itália bem como a Câmara Italiana de Comércio para todo o Norte e o Nordeste do Brasil graças à sua posição estratégica em relação à Europa além de possuir um dos cinco principais portos do país. O estado também contava com expressivas colônias italianas nas cidades de São Lourenço da Mata, Nazaré da Mata, Palmares, Garanhuns e Recife. Em Recife, a colônia italiana passou a exercer forte influência na economia,

4 O professor, historiador e geógrafo Manoel Correa de Andrade atuou como professor na Universidade Federal de Pernambuco (UFPE) e realizou diversas pesquisas sobre a presença italiana no Nordeste e Norte do Brasil. 
principalmente na indústria e no comércio. Para saber a situação do ensino da LI em Pernambuco, contatou-se o Centro Cultural Dante Alighieri. Há apenas uma cidade com ensino de LI em todo o estado de Pernambuco, que é Vicência. É interessante notar que foi promulgada uma lei municipal, de número 1407, em 15 de dezembro de 2006, que instituiu a inclusão da língua italiana na grade curricular do município de Vicência, caso único em todo o Norte e Nordeste do Brasil. O ensino de LI foi iniciado com cerca de 300 alunos do $9^{\circ}$ ano do ensino fundamental de 7 escolas municipais por professores formados pelo Centro de Línguas Modernas da cidade de Vicência, cujo ensino de LI é mantido pelo Centro Cultural Dante Alighieri.

De acordo com Andrade (2002), o estado do Ceará acolheu na primeira metade do século XX uma família dedicada ao comércio de calçados, mas após a 2a Guerra Mundial Fortaleza atraiu um grande número de imigrantes italianos. Atualmente muitos estão dedicados a atividades ligadas ao turismo e à hotelaria. Juntamente com a Bahia, o Ceará é o único estado da Federação que conta com uma universidade que oferece um curso de graduação em LI. As escolas públicas cearenses, tanto municipais quanto estaduais, não oferecem o ensino de LI aos alunos. Existe na cidade de Fortaleza um Centro de Línguas mantido pela prefeitura e que oferece, entre outros idiomas, o ensino de LI à comunidade em geral.

No estado do Rio Grande do Norte, a maior parte dos italianos se estabeleceu na cidade de Natal. De acordo com Andrade (2002), no início esses italianos se dedicaram a atividades ligadas ao artesanato e ao comércio e os italianos da segunda geração se destacaram como profissionais liberais de nível superior. Nos últimos anos, o estado também recebeu um grande número de italianos que aqui decidiram residir e trabalhar principalmente na área de turismo e hotelaria. A Associação Cultural Ítalo-Brasileira do Rio Grande do Norte (ACIBRA-RN), fundada em 2011, e o Centro di Cultura Italiana Madrelingua, que atua no estado desde 1997, mas não encontramos, em nosso levantamento, escolas públicas que oferecem cursos de italiano.

No estado de Alagoas, sabe-se da existência de uma expressiva colônia italiana em São José da Laje composta de pessoas que exerciam diferentes profissões, como alfaiates e cinzeladores, mas a maior parte se dedicava à venda de miudezas de casa em casa tanto no interior como na cidade. Nos últimos anos, assim como ocorreu no Rio Grande do Norte, um grande número de italianos se estabeleceu na capital e nas cidades do litoral alagoano para trabalhar na área de turismo e hotelaria. Em Alagoas, há o Centro Cultural Dante Alighieri Comitato Maceió-Brasil, mas parece não haver no estado escolas públicas que tenham o ensino de língua italiana.

Melo e Góes (2011), em um trabalho sobre a imigração italiana na Paraíba, mostram que os 
italianos que se estabeleceram no estado o fizeram especialmente na área urbana em meados do século XIX. Além da capital, João Pessoa, italianos instalaram-se também nas cidades de Areia, Mamanguape, Rio Tinto, Campina Grande, Santa Luzia, Patos, Guarabira, Pombal, Bonito de Santa Fé e Souza. Assim como nos outros estados do Nordeste, os italianos da Paraíba se dedicaram ao comércio, abrindo diversas lojas no Centro da capital João Pessoa e no bairro Varadouro no século XIX. Os italianos também tiveram forte influência na arquitetura dos edifícios de muitas cidades paraibanas e na música, especialmente na formação de instrumentistas, segundo os autores mencionados acima. Apesar de toda essa presença italiana no estado paraibano, há apenas o Centro Cultural Ítalo-Brasileiro Dante Alighieri (CCIBDA -comitato João Pessoa) e não encontramos escolas públicas que ofereçam o ensino de LI.

\section{A região Norte}

Assim como na região Nordeste, a imigração italiana na região Norte do Brasil não foi tão expressiva se comparada aos estados da região Sudeste e Sul do país. Entretanto, até mesmo nessa região com características tão distintas da península itálica, a presença italiana se fez sentir, especialmente nos estados do Pará e do Amazonas.

No final do século XIX, graças ao surgimento do ciclo da borracha na região Amazônica, o empresário e armador genovês Gustavo Gavotti criou uma companhia de navegação Ligure Brasiliana e com isso procurou estimular a vinda de italianos para o Pará, cuja capital Belém era a metrópole regional da época, graças a seu porto, centro de exportação e importação de produtos, de acordo com Andrade (2002). Apesar de ter havido uma tentativa de instalar uma colônia agrícola na Ilha do Mosqueiro, hoje um distrito administrativo do município de Belém, a maioria daqueles que se interessou em vir para a região Norte preferiu se dedicar a atividades urbanas, como o comércio e a prestação de serviços. Outros italianos, porém, se dedicavam a atividades artísticas como aqueles que tocavam instrumentos musicais nas reuniões noturnas de famílias abastadas ou aqueles que decoravam residências com suas pinturas.

Já na década de 30 do século XX, os italianos já se haviam espalhado para várias outras cidades da região Norte, além das capitais Belém e Manaus. Há registros de italianos em Tefé, Itacoatiara, Parintins, Santarém, Óbidos, Alenquer, Juruti e Oriximiná. A maior parte desses italianos provinha do sul da Itália e alguns da Toscana.

Apesar da presença italiana acima descrita, em nossos levantamentos, obtivemos a informação de que no estado do Amazonas não há ensino de LI em escolas públicas. 
Em Rondônia, o ensino de LI em escolas públicas foi promovido por cerca de oito anos, graças ao empenho do Circolo Italiano de Colorado do Oeste (CICOL). Inicialmente o ensino de LI foi implantado na grade curricular das escolas municipais de Colorado do Oeste, beneficiando alunos dos atuais $6^{\circ}, 7^{\circ}, 8^{\circ}$ e $9^{\circ}$ anos. Alunos de quatro e cinco anos que frequentavam o pré-escolar municipal também estudavam a LI. As aulas tinham a duração de duas horas e eram ministradas por professores que frequentaram o curso de formação ministrado pela FECIBESP. Posteriormente, o ensino de LI foi estendido para as cidades de Cacoal, Cerejeiras, Pimenta Bueno, Pimenteiras do Oeste e Vilhena. Digno de nota nesse projeto desenvolvido pelo CICOL foi o fato de ele beneficiar principalmente os alunos das áreas rurais e de baixa renda. No entanto, segundo informações do CICOL, o ensino de LI nas escolas públicas de todas essas cidades foi suspenso devido à falta de mão de obra, já que muitos professores foram aprovados em outros concursos do estado e deixaram de ministrar as aulas de LI. Em 2011, outro projeto foi implantado em 32 escolas públicas estaduais que tornava o ensino de LI disponível a esse público graças ao apoio financeiro de um empresário da região amazônica, sendo suspenso, porém, no final de 2013.

Não foi possível levantar dados a respeito do ensino de LI em escolas públicas dos estados de Amapá, Roraima, e Tocantins porque não foram encontrados vice-consulados da Itália, nem associações italianas nesses locais.

No estado do Acre há uma escola pública com ensino de LI na cidade de Rio Branco, a capital do estado. O ensino de LI é patrocinado pela Associação Ítalo-Brasileira Dante Alighieri de Rio Branco e é direcionado aos alunos do Colégio de Aplicação da Universidade Federal do Acre (UFAC).

\section{A Região Centro-Oeste}

Há pouquíssimos trabalhos que tratam da imigração italiana nos estados da região CentroOeste do Brasil. Cenni (2002) afirma que já em 1862 já se encontravam italianos na capital do Mato Grosso, Cuiabá, embora poucos tenham se estabelecido no estado. O autor menciona Manuel Cavassa, que veio a ser o fundador da importante cidade de Corumbá. A respeito dele o autor diz que "embora tivesse nascido em Lisboa, por ter pai italiano e por ter sido criado sob a tutela da nação sarda após ter ficado órfão com sete anos de idade, Manuel Cavassa se considerou e foi sempre considerado por todos como italiano". (CENNI, 2002, p. 194). Em um trabalho sobre a imigração italiana em Nova Veneza, Goiás, Souza (2012) declara que os primeiros 
italianos que chegaram ao estado, no ano de 1912, eram sete famílias todas consanguíneas ou formadas por matrimônio que vieram para trabalhar na agricultura. Apesar de ser um grupo pequeno, essas famílias tiveram tanta influência na formação social e cultural da região que hoje Nova Veneza é considerada um pedaço da Itália em Goiás, e a única colônia italiana do Centro-Oeste que mantém as tradições da península por meio de diversas iniciativas culturais, entre as quais, o Festival Gastronomia e Cultura de Nova Veneza, ocasião em que os habitantes da cidade se reúnem para comer comidas típicas, dançar e ouvir músicas italianas. Soares et al. (2011) mostram que a maior parte dos italianos ou de descendentes que residem atualmente nos estados do Centro-Oeste vieram dos estados do sul do Brasil, principalmente a partir da década de 70, por causa da falta de oportunidades nas regiões interioranas desses locais.

No Distrito Federal (DF), há a Associação Cultural Dante Alighieri de Brasília e não há escolas públicas que ofereçam o ensino de LI. No passado, tentou-se firmar uma parceria entre a Associação e a secretaria de educação do DF nos mesmos moldes do que acontece em outros estados, mas, infelizmente, o acordo não foi feito.

Em relação ao estado de Goiás, descobrimos que havia ensino de italiano em contexto público na cidade de Nova Veneza, graças ao trabalho de Souza (2011). Nessa cidade, desenvolve-se o "Projeto Italiano", implantado em 2008, no qual crianças do $3^{\circ}$ ao $5^{\circ}$ ano do ensino fundamental aprendem a LI no horário escolar. Apesar de a língua italiana estar inserida na grade horária, a LI não é inserida na grade curricular, e o único professor de italiano que ministra as aulas não é concursado. Em 2013, oito turmas do ensino fundamental eram contempladas com o ensino de LI.

No estado de Mato Grosso não foram encontradas associações italianas nem representantes do governo italiano que pudessem fornecer informações a respeito do ensino de LI em escolas públicas nesse estado.

No Mato Grosso do Sul, há o Centro Cultural Italiano de Mato Grosso do Sul (CCI) e também não encontramos nenhuma escola pública com ensino de LI.

Tendo elencado os municípios dos estados ou das regiões brasileiras ${ }^{5}$ que oferecem o ensino de italiano em escolas públicas, apresentaremos a seguir algumas conclusões acerca dos dados coletados.

5 Para uma visualização completa dos dados, ver no Apêndice a "Tabela dos municípios com oferta de italiano nas escolas públicas". 


\section{Conclusões}

Coletar dados referentes à situação do ensino público de italiano no Brasil não foi uma tarefa fácil, pois além das dificuldades advindas das extensas dimensões territoriais do país, nem sempre havia conhecimento por parte dos órgãos e das universidades acerca da presença do ensino de italiano nas escolas públicas que lhes estão próximas. Na busca por informações, foi necessário, em todos os estados da federação, contatar não apenas as universidades públicas, mas também as associações italianas, representantes consulares e, em alguns casos, os professores de italiano em serviço.

Apesar das dificuldades inerentes ao mapeamento proposto, acreditamos ter elencado grande parte dos municípios que oferecem o ensino de italiano no Brasil. A maioria deles concentrase nas regiões sul e sudeste, locais onde a imigração italiana foi significativamente superior em termos numéricos. Ressaltamos, entretanto, a presença de inciativas referentes ao ensino do italiano em escolas públicas de sete cidades de Rondônia, em Nova Veneza (Goiás) e em Vicência (Pernambuco); a primeira interrompeu o ensino de italiano em 2013, mas as duas últimas continuam esse trabalho.

Os dados apresentados deixam claro duas questões importantes para estudiosos da área de Italianística no Brasil. A primeira diz respeito ao fato de que há aproximadamente 90 municípios com oferta de italiano em escolas públicas, mas essa oferta encontra-se em declínio: 15 cidades interromperam os cursos de italiano oferecidos a alunos da rede pública no período de 2008 a 2013, nos estados de Rondônia e Espírito Santo, além das três escolas do Rio de Janeiro que interromperam o ensino de italiano. A outra questão digna de nota é o fato de que a quase totalidade das inciativas contam com o apoio das prefeituras e das associações italianas, o que nos faz apontar para a necessidade de repensar o papel das universidades públicas, principalmente aquelas com Graduação em Letras-Italiano, dado seu aparente distanciamento em relação às escolas municipais e estaduais no tocante a projetos educacionais ligados ao ensino de italiano.

O presente mapeamento ${ }^{6}$ representa não apenas um convite para a identificação de outros municípios onde há ensino de italiano em contexto público e que não foram aqui mencionados, mas também, para o desenvolvimento de futuras pesquisas relacionadas à formação dos professores, ao uso da língua italiana nas comunidades próximas às escolas com oferta de italiano, ao papel das associações italianas e das universidades na construção de projetos educacionais etc. Tais pesquisas poderão trazer subsídios para compreender como se dá a

6 Agradecemos ao Dirigente Scolastico do Consulado Italiano de São Paulo, Augusto Bellon, à Profa. Dra. Marisa da Silva Moraes (UFES), às Secretarias Municipais de Educação e às Associações Ítalo-brasileiras presentes nos diversos estados do Brasil pelos preciosos dados fornecidos. 
presença do italiano nos mais variados contextos, e também, para a elaboração de programas de difusão - e manutenção, da língua e da cultura italiana no território brasileiro.

\section{Referências}

ANDRADE, M. C. D. Os italianos no trópico: presença italiana no norte e no nordeste do Brasil. Passo Fundo: UPF, 2002.

BALTHAZAR, L. L. Um olhar investigativo sobre as atividades orais de livros didáticos destinados a iniciantes de língua italiana. 2009. 123 f. Dissertação (Mestrado em Educação). Florianópolis: CEDUFSC, 2009.

BRASIL. Secretaria de Educação Fundamental. Parâmetros Curriculares Nacionais/Secretaria de Educação Fundamental. Brasília: MEC/SEF, 1997.

BRASIL. Lei de Diretrizes e Bases da Educação Nacional: nº 9394/96. Brasília, 1996.

CAIRA, R. O italiano falado em Curitiba por um grupo de falantes nativos que vivem no Brasil há cerca de cinquenta anos. 2009. 88 f. Dissertação (Mestrado em Letras). São Paulo: FFLCH-USP, 2009.

CENNI, R. Italianos no Brasil “Andiamo in Merica”. São Paulo: Edusp, $3^{\text {a }}$ ed. 2002.

DERENZI, L. S. Os italianos no Espírito Santo. Rio de Janeiro: Artenova, 1974.

GRECO, A. A. Em busca de braços fecundantes: política, economia e preconceito no discurso da imprensa mineira sobre a imigração (1888-1898). 2009. 133 f. Dissertação (Mestrado em História Social). São Paulo: FFLCH-USP, 2009.

MELO, T. S. D.; GOÉS, K. R. D. Processos imigratórios no Brasil: a inversão do ciclo migratório italiano na Paraíba. In V Congresso Internacional de História, Paraná: UEM, 2011, pp. 228-233.

http://www.cih.uem.br/anais/2011/trabalhos/163.pdf

PAIVA, V. P. História da educação popular no Brasil: educação popular e educação de adultos. São Paulo: Edições Loyola, 2003.

SOUZA, I. G. D. A imigração italiana, séculos XIX-XX, em Nova Veneza-GO: contribuições para a cultura. In Revista Visão Acadêmica, Cidade de Goiás, UEG: Ano 2, n 5: 116-136, novembro 2012.

SOARES, W. et al. Italianos no Brasil: síntese histórica e predileções territoriais. In Revista Educação 
e Fronteiras, Dourados, UFGD: v.13, nº 23: 171-199, jan./jun. 2011.

TRENTO, A. Do outro lado do Atlântico. Um século de imigração italiana no Brasil. São Paulo: Nobel, 1989.

\section{Sitografia}

http://www.saocaetanodosul.sp.gov.br/interna.php? site=1\&conteudo=125 Acesso: 15/02/2013.

http://www.educacao.sp.gov.br/portal/projetos/centros-de-estudos-de-linguas Acesso: 15/02/2013.

http://www.lem.seed.pr.gov.br/modules/conteudo/conteudo.php?conteudo=355 Acesso: 22/02/2013.

http://www.italiaamica.com.br/ Acesso: 14/03/2013.

http://dantealighierirecife.blogspot.com.br/2013/07/cursos-de-italiano-em-recife.html Acesso: 02/03/2013.

http://www.centroculturalladante.com/quemsomos.php Acesso: 07/03/2013.

http://br.groups.yahoo.com/neo/groups/acibra_rn/info Acesso: 07/03/2013.

http://www.dantealighieribsb.com.br/quem.htm Acesso: 09/03/2013.

http://culturaitaliana.webs.com/ Acesso: 09/03/2013.

http://www.fundacaotorino.com.br/ei/a-fundacao-torino/historial Acesso: 02/02/2013.

http://www.fecibesp.org.br/sitelquem.php Acesso: 08/02/2013.

http://culturaitaliana.webs.com/ Acesso: 04/04/2013.

http://www.ccims.com.br/home/ Acesso: 04/04/2013. 


\section{Apêndice}

Tabela dos municípios com ensino de italiano nas escolas públicas

\begin{tabular}{|c|c|c|}
\hline Estado ou região do Brasil & $\begin{array}{l}\text { Municípios com oferta de italiano } \\
\text { em escolas públicas }\end{array}$ & $\begin{array}{l}\text { Fonte de recurso (financeiro ou } \\
\text { didático-pedagógico) }\end{array}$ \\
\hline Rio Grande do Sul & $\begin{array}{l}\text { No horário escolar: Antonio Prado, } \\
\text { Aratiba, Caxias do Sul, Coqueiro } \\
\text { Baixo, Doutor Ricardo, Farroupilha, } \\
\text { Imigrante, Nova Brescia, Porto } \\
\text { Alegre, São Marcos e Serafina } \\
\text { Correa. } \\
\text { No contraturno: Bento Gonçalves, } \\
\text { Faxinal do Soturno, Nova Prata, } \\
\text { Nova Roma do Sul, São João do } \\
\text { Polesine, Veranópolis e Vista Alegre } \\
\text { do Prata. }\end{array}$ & ACIRS e Prefeitura \\
\hline Santa Catarina & $\begin{array}{l}\text { No horário escolar: Arroio Trinta, } \\
\text { Laurentino, Morro Grande, Nova } \\
\text { Veneza, Salto Veloso e Siderópolis. } \\
\text { No contraturno: Balneário } \\
\text { Camboriú, Concórdia, Jaborá, } \\
\text { Jaraguá do Sul, Joinville, Mafra e } \\
\text { Massaranduba. }\end{array}$ & CCI e Prefeituras \\
\hline \multirow[t]{2}{*}{ Paraná } & $\begin{array}{l}\text { No horário escolar: Curitiba e } \\
\text { Mandirituba. } \\
\text { No contraturno: } \\
\text { Coronel Vivida, Curitiba (algumas } \\
\text { escolas), Palmas, Rio Negro, São João } \\
\text { e São José dos Pinhais. }\end{array}$ & CCI e Prefeituras \\
\hline & $\begin{array}{l}\text { Escolas estaduais: Cascavel, Céu } \\
\text { Azul, Corbélia, Curitiba, Francisco } \\
\text { Beltrão, Ibaiti, Maringá, Santa Tereza } \\
\text { D’Oeste, São Jerônimo da Serra, } \\
\text { Siqueira Campos, Toledo, Vera Cruz } \\
\text { do Oeste. }\end{array}$ & $\begin{array}{l}\text { Secretaria de Educação do Estado } \\
\text { e Centro de Línguas Estrangeiras } \\
\text { Modernas (CELEM). Aulas a } \\
\text { alunos, professores, e a membros da } \\
\text { comunidade. }\end{array}$ \\
\hline
\end{tabular}




\begin{tabular}{|c|c|c|}
\hline \multirow[t]{2}{*}{ Espírito Santo } & Domingos Martins e Santa Tereza & \\
\hline & $\begin{array}{l}\text { Até 2013: } \\
\text { Vitória, Venda Nova do Imigrante, } \\
\text { Vila Velha, Castelo, Alfredo Chaves } \\
\text { e Cachoeiro de Itapemirim. } \\
\text { Até 2009: } \\
\text { Vargem Alta e Nova Venécia. }\end{array}$ & ALCIES e Prefeituras \\
\hline Minas Gerais & Belo Horizonte & $\begin{array}{l}\text { Fundação Torino (Centro di Lingua e } \\
\text { Cultura Italiana) }\end{array}$ \\
\hline \multirow{2}{*}{ Rio de Janeiro } & Rio de Janeiro & Secretaria Estadual de Educação \\
\hline & $\begin{array}{l}\text { Rio de Janeiro: } \\
\text { Até 2012: "Escola Itália": } \\
\text { Até 2008: } \\
\text { "Escola Pio X" e "Escola } 25 \text { de } \\
\text { abril". }\end{array}$ & $\begin{array}{l}\text { Secretaria Municipal de Educação e } \\
\text { ACIB - RJ }\end{array}$ \\
\hline \multirow[t]{6}{*}{ São Paulo } & São Paulo & $\begin{array}{l}\text { Secretaria Municipal de Educação e } \\
\text { FECIBESP }\end{array}$ \\
\hline & $\begin{array}{l}\text { Centros de Línguas (CELs): } \\
\text { Araçatuba, Araraquara, Assis, } \\
\text { Avaré, Carapicuíba, Fernandópolis, } \\
\text { Guarulhos, Jales, Santa Fé, José } \\
\text { Bonifácio, Mirassol, Nova Granada, } \\
\text { Jundiaí, Marília, Osasco, São José } \\
\text { do Rio Preto, São José dos Campos, } \\
\text { São Paulo, São Vicente, Suzano, } \\
\text { Taquaritinga, Taubaté e Tupã. }\end{array}$ & $\begin{array}{l}\text { Secretaria Estadual de Educação } \\
\text { Secretaria Municipal de Educação e } \\
\text { FECIBESP }\end{array}$ \\
\hline & $\begin{array}{l}\text { Amparo } \\
\text { Campos do Jordão }\end{array}$ & 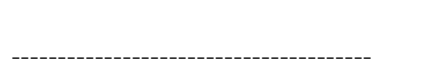 \\
\hline & São Paulo & Prefeituras \\
\hline & $\begin{array}{l}\text { São Caetano do Sul } \\
\text { Pedrinhas Paulista }\end{array}$ & \\
\hline & $\begin{array}{l}\text { Jundiaí (ensino gratuito, mas não } \\
\text { apenas a alunos da rede pública, mas } \\
\text { a toda a comunidade). }\end{array}$ & \\
\hline Região Nordeste & $\begin{array}{l}\text { Pernambuco (Vicência: } 7 \text { escolas, } \\
\text { italiano na grade curricular) }\end{array}$ & Centro Cultural Dante Alighieri \\
\hline
\end{tabular}


Região Norte

Nova Veneza (Goiás)

Região Centro-oeste
Secretaria Estadual de Educação e

Empresa privada

Associação Dante Alighieri e Colégio de Aplicação da UFAC

Prefeitura de Nova Veneza 